Revista Destaques Acadêmicos, Lajeado, v. 10, n. 1, 2018. ISSN 2176-3070

DOI: http://dx.doi.org/10.22410/issn.2176-3070.v10i1a2018.1781

http://www.univates.br/revistas

\title{
COMUNICAÇÃO ESTRATÉGICA DIGITAL: ESTUDO SOBRE EMPRESAS DO VALE DO TAQUARI/RS
}

\author{
Rosane Sott Bona ${ }^{1}$, Gerson José Bonfadini ${ }^{2}$
}

Resumo: Este estudo tem por objetivo identificar como as empresas do Vale do Taquari utilizam a comunicação estratégica digital para se relacionarem com os seus clientes. $\mathrm{Na}$ metodologia realizou-se uma pesquisa descritiva, bibliográfica, documental e quantitativa. Utilizou-se um questionário, enviado por meio do Formulário do Google para setenta empresas cadastradas no sistema do SENAI de Lajeado/RS, obtendo-se um retorno de $26 \%$, sendo que os dados foram tabulados e analisados no software Microsoft Office Excel 2013. Os resultados demonstram que as empresas atuam nos três ramos: indústria, comércio e serviços, tendo faturamento variado. Os públicosalvo que mais se destacaram foram adultos e jovens, porém a maioria das empresa não tem pessoal designado para trabalhar com comunicação estratégica digital e faz atualizações dos meios de comunicação digital, principalmente, semanalmente e mensalmente, ao mesmo que pouco investe em comunicação digital, todavia utilizam especialmente meios gratuitos de comunicação: Facebook, Whatsapp e Instagram. E todas de alguma forma realizam análises do alcance da comunicação, geralmente por meio do Google Analistics. A grande maioria dos respondentes tem conhecimento do que é comunicação estratégica digital, também revelam que poucas empresas adotam-na, sendo que as que adotam realizam através de trabalhos com planejamento, patrocínios, impulsionamentos e anúncios. Apontam como vantagens desse novo processo de comunicação: melhoria da imagem da empresa, aumento das vendas e dos clientes, maior velocidade na transmissão das informações, além disso, o alcance das informações e ações também é maior. Igualmente, poucos percebem desvantagens da comunicação digital e os que assinalam inferem: problemas com falsas mídias, diminuição do contato com o cliente, problemas com comentários e rejeições à marca ou aumentado os custos de comunicação.

Palavras-chave: Comunicação; Estratégia digital; Marketing; Relacionamento com o cliente.

1 Graduanda do Curso de Pós-Graduação MBA em Marketing da Universidade do Vale do Taquari - Univates, Lajeado/RS. E-mail: rosane.sottbona@gmail.com.

2 Doutor em Comunicação Social (PUC/RS). Professor da Universidade do Vale do Taquari Univates, Lajeado/RS. E-mail: bonfadini@univates.br. 


\section{INTRODUÇÃO}

O processo de globalização influencia na gestão das organizações, da mesma forma a informação cria parâmetros no relacionamento entre as pessoas e as empresas. Assim, ter estratégias para gerir as organizações e as relações que elas têm com o mercado consumidor, concorrencial e de fornecedores tornou-se relevante para manter-se competitivo dentro do setor que atua. Segundo Ribeiro (2014), com o surgimento da internet, as empresas passaram a criar novas ferramentas de comunicação com seus clientes e público-alvo, desenvolvendo sites, blogs, páginas de internet, atuando com e-mails, redes e mídias sociais.

A utilização de meios digitais como ferramenta de comunicação proporciona às empresas maior abrangência sobre o que ela quer comunicar, sejam propagandas, ações de vendas ou, mesmo, conhecer o ambiente que está inserida. Deste modo, a questão que norteará esta pesquisa é: Quais são as estratégias de comunicação digital utilizadas pelas empresas do Vale do Taquari?

Destarte, este estudo visa identificar como as empresas do Vale do Taquari utilizam a comunicação estratégica digital para se relacionar com os seus clientes. Tendo como objetivos específicos: compreender o perfil das empresas do Vale do Taquari; avaliar como as empresas atualizam a comunicação estratégica digital; e entender como as empresas do Vale do Taquari se relacionam com os clientes.

O estudo justifica-se pela importância que a comunicação estratégica digital tem nesta era da informação, exigindo adequação das empresas para manter-se no mercado e fidelizar seus clientes. Além disso, é assunto de interesse desta estudante, que por meio deste estudo compreende teoria e prática. Outrossim, torna-se fonte para novas pesquisas sobre o assunto.

\section{REFERENCIAL TEÓRICO}

\subsection{Comunicação organizacional}

O processo de comunicação organizacional envolve marketing, para a American Marketing Association, o marketing envolve "o processo de planejar e executar a concepção, estabelecimento de preços, promoção e distribuição de ideias, produtos e serviços a fim de criar trocas que satisfaçam metas individuais e organizacionais" (CHURCHILL; PETER, 2000, p. 4).

Adentrando no entendimento da comunicação organizacional, destacase que Kunsch (2009) esclarece que esta é um meta-sistema que estuda as interrelações dos conhecimentos e das práticas no processo de comunicação que envolve empresa, sociedade e redes de relacionamento. Ainda, o autor enfatiza que a comunicação é fundamental para que a administração das organizações 
tenha sentido e significado, devendo ser realizada de forma planejada, com ações coordenadas, direção e controle de políticas que integrem a empresa com suas redes de relacionamento. Por meio de processos de comunicação as empresas criam mensagens que devem considerar o ambiente organizacional, o perfil do receptor ou público-alvo e os canais de comunicação para dialogar as informações.

Entendemos por comunicação integrada uma filosofia que direciona a convergência das diversas áreas permitindo uma atuação sinérgica. Pressupõe uma junção da comunicação institucional, da comunicação mercadológica, da comunicação interna e da comunicação administrativa, que formam o mix, o composto da comunicação organizacional (KUNSCH, 2009, p. 150).

A comunicação organizacional envolve diversos fatores, permeia por um emaranhado de compreensões, ou seja, as empresas precisam entender o meio que está inserida e as nuances que interferem no seu processo de comunicação. Henrique (2018) elenca alguns tipos de comunicação organizacional:

Comunicação Interna: que é voltada para o público interno (colaboradores, prestadores de serviços e terceirizados), nesta transmite-se informações fundamentais com segurança, objetividade e com pouco ruído. Outrossim, ela pode melhorar o clima no ambiente de trabalho, reter talentos com ações de endomarketing e contribui para o entendimento da cultura organizacional. Esta pode ser dividida em três tipos: ascendente (vem de baixo para cima, dos funcionários para os líderes), descendente (de cima para baixo, dos líderes para os funcionários, não necessariamente com autoritarismo) e horizontal (entre trabalhadores de mesmo nível hierárquico).

Comunicação Externa: é por meio desta modalidade que a empresa é reconhecida pelos consumidores, pela comunidade e pelos fornecedores, expressando valores, visão e cultura, além de informar sobre novidades, novos projetos, inovações, novos produtos, e tudo que possa atrair a atenção do público-alvo. A comunicação externa engloba a comunicação mercadológica (ações voltadas aos consumidores, buscando melhorar vendas, a imagem dos produtos/serviços) e a comunicação institucional (trabalha a imagem da empresa diante da sociedade e do mercado, tem foco no posicionamento da marca).

Comunicação baseada no Endomarketing: envolve o desenvolvimento de planos de treinamentos, desenvolvimento, cursos, etc. para os colaboradores, buscando capacitá-los para trabalhar com os clientes visando atingir os resultados da empresa. Desta forma, cria-se um clima organizacional agradável, estimulante, propício ao desenvolvimento e bem-estar, o que, por sua vez, reflete nos produtos e serviços prestados aos clientes. 
Lima e Abbud (2015, p. 11-12, grifo dos autores) trazem três dimensões da comunicação nas relações organizacionais:

A organização comunicada caracteriza-se, fundamentalmente, pela fala oficial da organização [...].

A organização comunicante [...] parte do princípio de que o mais importante, nesse processo, é a competência interpretativa da alteridade, isto é, dos públicos com os quais a organização se relaciona.

A organização falada refere-se aos processos de comunicação informal indiretos; aqueles que se realizam fora do âmbito organizacional, mas que dizem respeito à organização.

Além disso, Henrique (2008) declara que a comunicação organizacional possibilita maior interatividade que proporciona feedbacks frequentes e assertivos, maior participação dos colaboradores da empresa e do público-alvo e respeito à instituição. $\mathrm{O}$ autor elenca alguns canais utilizados no processo de comunicação organizacional: jornal, mural, televisão corporativa, intranet, rede social corporativa, blog, newsletter, boletim, e-mail, videoconferência, reuniões, seminários, rádio corporativa, etc.

\subsection{Comunicação digital}

Na compreensão de Nasser (2006, p. 53):

No ambiente complexo em que hoje operam as empresas, dominado pela globalização dos negócios e a multiplicidade de mídias, o desafio de garantir o discurso corporativo único torna-se cada dia mais difícil de vencer. [...] há uma proliferação espantosa de meios e formas de comunicação, [...] é certo que a revolução digital e a expansão das mídias interativas facilitam e dinamizam, de maneira extraordinária, o relacionamento das companhias com seus públicos de interesse.

Machado (2012) destaca que a internet é a espinha dorsal do processo de comunicação no mundo, tornando-se meio de comunicação universal nesta era da informação. Para Fassá e Kegler (2008, p. 266, apud MACHADO, 2012, p. 37):

[...] a internet, como mídia de convergência de instâncias interacionais e de linguagem, não é exclusivamente do campo midiático, podendo ser gerenciada pelas próprias instituições [...] e sujeitos que interagem permanentemente no espaço midiatizado. Nesse contexto, as organizações são ativamente responsáveis tanto pela inter-relação com a mídia, com vistas a dar visibilidade a seus princípios, como pela autogerência de sua visibilidade, através de 
estratégias de comunicação organizacional, em materialidades que podem ser dispostas diretamente ao público, sem a interferência ou elo determinado pelos meios de comunicação tradicionais.

O processo de comunicação digital exige gestão para obter sucesso em tempos que o babel tecnológico demanda alinhamento, sendo este também um ponto crítico neste gerenciamento que deve ocorrer em nível estratégico alinhando conceitos e imagem, além disso, não devem ocorrer desarmonias entre o que comunica-se para o público interno e para o mercado (NASSER, 2006).

Neste contexto, há a World Wide Web (web) que assemelha-se a uma teia que conecta pessoas e documentos por meio da internet, facilitando a troca de informações em plataformas operacionais (ARAUJO, 2011). A web tornou-se um imenso banco de dados que caracteriza-se por fases:

A web 1.0 pode ser caracterizada pelo uso das tecnologias básicas que deram origem à web: o sistema de endereçamento baseado em URL, o protocolo de comunicação baseado em hipertexto e a linguagem HTML. Nessa fase, as organizações utilizavam a web para se apresentar e mostrar seus objetivos e seus principais integrantes.

$[\ldots]$

A web 2.0 significa apenas que tem muito mais gente se apropriando da tecnologia da internet, o que a torna um fenômeno social de massa. Significa que não é mais necessário recorrer a intermediários ou técnicos (ARAUJO, 2011, p. 3).

Machado (2012) enfatiza que a comunicação passou a ser redirecionada no atual contexto da midiatização, exigindo das empresas novas possibilidades sociotécnicas que presumem a necessidade de interagir com o público e não simplesmente estar visível na mídia. A comunicação digital caracteriza-se como fenômenos de comunicação digital, ou seja, as manifestações da comunicação humana que acontecem no ambiente da internet; além disso, ela apresenta-se como um processo de comunicação que ocorre em rede e de forma interativa, onde a distinção entre emissor e receptor é substituída por fluxos informativos entre internautas e redes, criando um processo comunicativo entre sites, blogs, comunidades virtuais, entre outros, os conteúdos disponibilizados e as pessoas (MACHADO, 2012).

\subsection{Relacionamento com o cliente}

Barbeiro (2010) sustenta que as empresas e seus líderes precisam ter coerência entre o que dizem e o que fazem, uma comunicação eloquente equilibra comunicação-coerência-confiança. Outrossim, ter uma comunicação 
correta com o cliente impulsiona a percepção que este faz da empresa e é determinante na ascensão e liderança da marca no mercado.

Ter uma opinião favorável perante o público, seja interno ou externo, é fundamental, assim sendo, as empresas criam estratégias de relacionamento que almejam aplicar ações que impactem nas questões institucionais. Desta forma, mobilizam relacionamentos duradouros e eficientes com relação aos interesses da empresa, qualquer manifestação que chega ao mercado precisa ser pensada por meio de instrumentos, habilidades e atitudes que agregam valor à marca/produto/serviço (KUNSCH, 2009).

\subsection{Estratégias de comunicação digital}

As estratégias de comunicação digital exigem a gestão de meios e conteúdos e requerem inteligência e mecanismos de comparação que envolvem modernos sistemas de gerenciamento integrado, ou seja, é preciso pesquisar e planejar, sendo que uma respalda a outra (NASSER, 2006). Segundo Machado (2012, p. 26-27), as estratégias de comunicação digital são:

[...] um conjunto de ações empreendidas nesses novos espaços de práticas midiáticas com a finalidade de estabelecer relações entre organização e público por meio da negociação e do diálogo. [...] as estratégias midiáticas correspondem a táticas e ações que visam maximizar as oportunidades das empresas no mercado.

Ainda, destaca-se que os paradigmas que envolvem as estratégias de comunicação digital passa pela disseminação da informação, pelo diálogo de um para outro ou muitos, sendo caracterizada por uma via de mão dupla e pelo processo da interatividade. Também, exige conectividade permitindo a transferência de informação; demanda heterogeneidade na interconexão dos sistemas; permite navegação que torna-se uma comunicação não-linear; comporta instantaneidade e velocidade, comunicação em rede, presença e disponibilidade de informação (constante e ininterrupta); alcance mundial, consulta rápida e fácil; personalização e acesso (MACHADO, 2012).

Para Schuler (2004) as estratégias de comunicação digital envolvem manter um sistema ativo de relacionamento com o público-alvo, normalmente, há um departamento dedicado ao relacionamento com o cliente, porém deve-se ter cuidado para que o vínculo com o cliente seja bem construído e duradouro; deve-se produzir um bom conteúdo que precisa ser contínuo, de alta qualidade, com inovações, informações relevantes e fontes confiáveis; é necessário analisar as métricas através de relatórios constantes que buscam desenvolver estratégias de inteligência com o mercado; e, também, ter bom senso e conhecimento do público, ou seja, conhecer as peculiaridades, administrar as redes, ter táticas de comunicação definidas e tomar decisões assertivas. 
Cerqueira e Silva (2011) enfatizam que no âmbito da estratégia de comunicação digital é fundamental conhecer e mensurar esta comunicação, assim sendo, a comunicação digital deve ser estrategicamente alinhada com os objetivos de comunicação do negócio. É preciso pré-definir os dados a serem publicados e as ferramentas de análise, é fundamental adotar métodos de avaliação do que está na rede e deve-se avaliar estrategicamente os dados resultantes, buscando identificar correlações, motivos, desdobramentos, consequências e variações de forma a elaborar ações corretivas e recomendações sobre o processo de comunicação digital.

Corrêa (2009, p. 170, apud ARAUJO, 2011, p. 6) destaca as três vertentes da comunicação digital:

[...] o campo da Comunicação fez com que termos como interatividade (a possibilidade do usuário de interagir com a informação disponibilizada no meio digital), multimedialidade (capacidade, outorgada pelo suporte digital, de combinar na mesma mensagem pelo menos um dos seguintes elementos: texto, imagem e som) e hipermedialidade (capacidade de interconectar diversos textos digitais entre si) passassem a integrar a rotina do processo comunicativo nos ambientes corporativos, institucionais, midiáticos e sociais.

No âmbito da web, há métricas que demonstram os sentimentos em relação a marca, que pode ser positivo, negativo ou neutro, onde pode-se analisar:
a) taxa de rejeição de um site - o percentual de visitantes que deixaram o site na primeira página;
b) tempo de navegação - o tempo que o visitante passou dentro do site;
c) conversões em vendas - relação entre o número de visitantes e o volume de vendas obtido;
d) geração de tráfego de onde chegam os visitantes do site;
e) número de impressões de um anúncio - quantidade de vezes que um anúncio (banner, flyer, etc.) foi visualizado pelos visitantes;
f) CTR's [click-through rate] - relação entre o número de impressões e o número de cliques num anúncio;
g) número de visitantes únicos em um site - quantidade real de visitantes que acessou o site. Um mesmo visitante pode acessar um determinado site várias vezes e todas elas são contabilizadas. Em geral, os sistemas verificam a unicidade do visitante pelo seu número IP;
h) monitoramento de menções e comentários em mídias sociais é uma análise mais complexa, porque sai do campo meramente quantitativo e envolve questões de ordem qualitativas. Pois tão importante quanto saber quantas vezes o objeto de monitoramento 
foi mencionado ou comentado, é saber o conteúdo do que se veiculou sobre ele (TELLES, 2011, p. 88-89, grifo nosso).

Ainda, existem questões que precisam ser analisadas para a interpretação dos resultados, que envolve a avaliação do relatório métrico das ações de comunicação digital, onde é preciso monitorar a reputação do usuário, ou seja, a capacidade do usuário/cliente de transmitir confiança e formar opinião e conteúdo (TELLES, 2011). Lock e Baldissera (2010, p. 5) declaram que o termo image-markers (imagem pública) envolve três elementos para a idealização de uma marca ou perfil: "mensagem (atos de fala, construções ideológicas, etc.), fatos (habilidades de ação) e configurações significativas (apresentação visual)".

Outrossim, Cerqueira e Silva (2011) enfatizam que as estratégias de comunicação digital envolvem métricas que servem de parâmetros para a tomada de decisão, sendo elas: o alcance que envolve o grau efetivo da disseminação de determinado conteúdo ou do potencial que um perfil tem; o engajamento que refere-se ao grau de participação que um perfil ou grupo tem sobre um tema ou assunto; a influência que alude sobre o grau de atenção e mobilização que um determinado perfil ou conteúdo gera sobre outros; e a adequação que abrande o grau de proximidade de um grupo, conteúdo ou perfil tem com características e valores almejados.

\section{PROCEDIMENTOS METODOLÓGICOS}

Este estudo é caracterizado como uma pesquisa descritiva, pois este estudo busca-se compreender o processo de comunicação estratégica digital das empresas do Vale do Taquari, ou seja, uma população específica, com características determinadas e que têm relação. Segundo Chemin (2015, p. 58) a pesquisa descritiva visa "descrever as características de determinada população ou fenômeno, ou estabelecer relações entre variáveis".

Também é uma pesquisa bibliográfica, que envolve as consultas de trabalhos, livros, sites, entre outros, para a fundamentação teórica; e uma pesquisa documental, que abrange a consulta no banco de dados do SENAI da cidade de Lajeado/RS. Segundo Marconi e Lakatos (2003, p. 158), “a pesquisa bibliográfica é um apanhado geral sobre os principais trabalhos já realizados, revestidos de importância, por serem capazes de fornecer dados atuais e relevantes relacionados com o tema"; e a pesquisa documental é uma "fonte de coleta de dados que está restrita a documentos, escritos ou não, constituindo o que se denomina de fontes primárias. Estas podem ser feitas no momento em que o fato ou fenômeno ocorre, ou depois" (MARCONI; LAKATOS, 2003, p. 174). A abordagem do estudo é quantitativa, que "representa aquilo que pode ser medido, mensurado, contado; exige descrição rigorosa das informações obtidas" (CHEMIN, 2015, p. 57), desta forma os dados são quantificados e os resultados são generalizados para a população em estudo. 
Para tal, é utilizado um questionário com questões abertas e fechadas, segundo Marconi e Lakatos (2003) o questionário envolve ordenar sistematicamente perguntas que são respondidas por escrito sem a presença do entrevistador. Os autores destacam que a elaboração do questionário exige cuidado na seleção das questões, deve-se cuidar a extensão do questionário e ser de fácil compreensão para o público-alvo (aplicação de pré-teste antes da aplicação definitiva é fundamental). As questões abertas permitem ao investigado responder livremente, expondo sua opinião com linguagem própria; já as questões fechadas o informante deve escolher entre as alternativas fixadas pelo pesquisador (MARCONI; LAKATOS, 2003).

O questionário foi enviado por e-mail, utilizando a ferramenta de Formulários do Google, a todas as empresas do Vale do Taquari que constam na base de dados do SENAI de Lajeado/RS e tem seus endereços de e-mails constantes do cadastro. Na base de dados do SENAI constam setenta e seis empresas, das quais seis não tem contato de e-mail. Das setenta empresas contatadas obteve-se um retorno de $26 \%$, ou seja, 18 empresas, no período de 16 a 21 de fevereiro de 2018. O pré-teste foi realizado com cinco pessoas, realizando-se os ajustes e correções apontadas pelos mesmos, de forma a garantir o entendimento do questionário pelo público-alvo.

A análise de resultados foi realizada por meio de planilhas e gráficos desenvolvidos no software Microsoft Office Excel 2013, onde as questões foram exportadas do formulário do Formulário do Google para o software, analisadas, contadas e trabalhadas em gráficos que são detalhados no próximo capítulo.

A pesquisa teve limitações que envolvem o pouco tempo disponível para o levantamento de dados em função do prazo de entrega do artigo e impossibilidade de contato pessoalmente por parte da pesquisadora em decorrência de problemas pessoais. Apesar disso, pode-se dizer que o número de respostas foi significativo.

\section{RESULTADOS}

Por meio da aplicação de um questionário buscou-se identificar como as empresas do Vale do Taquari utilizam a comunicação estratégica digital para se relacionar com seus clientes. Primeiramente, teve-se o intuito de conhecer os entrevistados e a empresa, para posteriormente aprofundar no contexto da comunicação estratégica digital.

Destaca-se que os setores de atuação dos respondentes são variados, mas pode-se evidenciar que $33 \%$ atuam na diretoria da empresa, $22 \%$ no setor de marketing e $22 \%$ no comercial, $11 \%$ na área financeira, $6 \%$ na gerência e $6 \%$ são micro empreendedores individuais, ainda, não houve respostas para os setores da contabilidade e de relações públicas. 
Gráfico 1 - Setor de atuação dos entrevistados

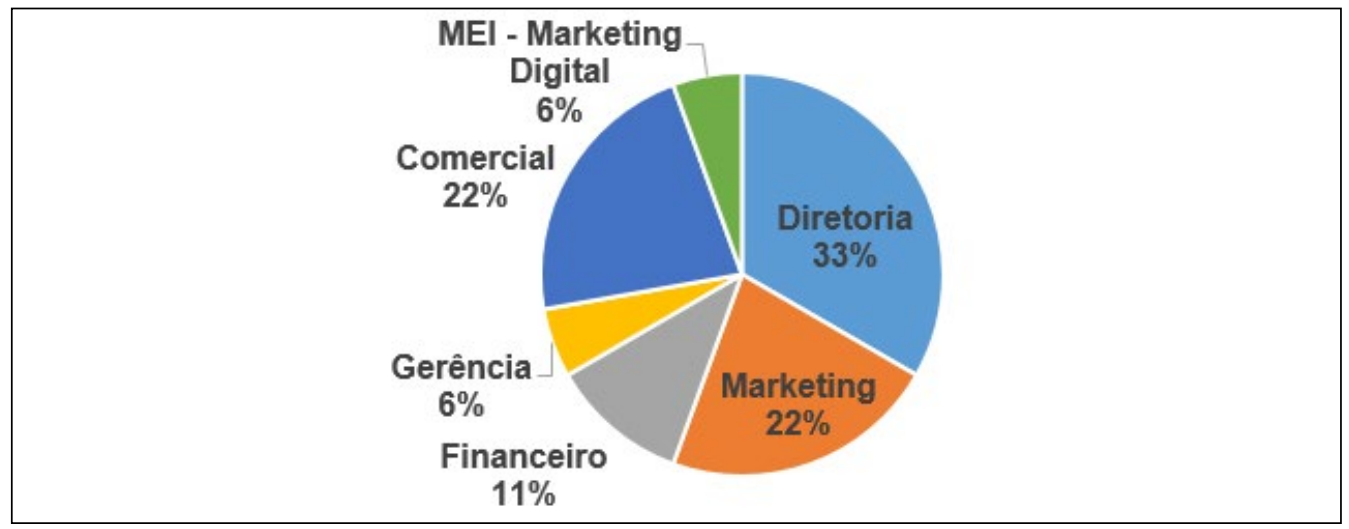

Fonte: Da autora (2018).

Com relação ao faturamento da empresa, sabe-se que $39 \%$ faturam até $R \$ 100.000,00$ mensais e $33 \%$ faturam entre $R \$ 100.000,01$ e $R \$ 500.000,00$ mensais; são poucas as empresas que faturam mais de $\mathrm{R} \$ 10.000 .000,01$ mensais (11\%); ainda temos percentuais menores para faturamentos entre $\mathrm{R} \$ 500.000,01$ a $\mathrm{R} \$ 1.000 .000,00(5 \%)$, e $6 \%$ para cada faturamento a seguir: $\mathrm{R} \$ 1.000 .000,01 \mathrm{a}$ $\mathrm{R} \$ 5.000 .000,00$ e $\mathrm{R} \$ 5.000 .000,01$ a $\mathrm{R} \$ 10.000 .000,00$.

Gráfico 2 - Faturamento das empresas

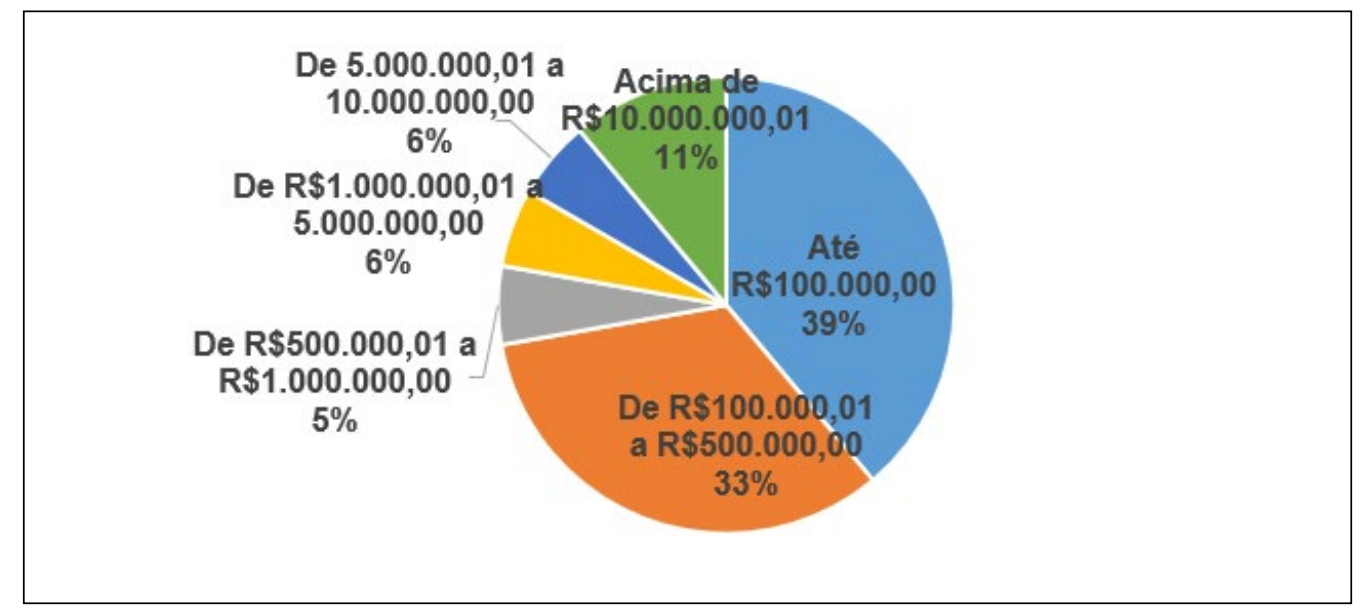

Fonte: Da autora (2018).

Com relação ao ramo em que a empresa atua, destaca-se que 50\% atua no setor de serviços, $28 \%$ na indústria e $22 \%$ no comércio. Pondera-se o entendimento do Sebrae (2018) sobre cada ramo de atuação, a indústria envolve a transformação de matéria prima em mercadoria; o comércio são empresas que 
compram de um produtor (indústria por exemplo) e vendem ao consumidor final; já no âmbito dos serviços é ofertado o próprio trabalho ao consumidor.

Gráfico 3 - Ramos de atuação da empresa

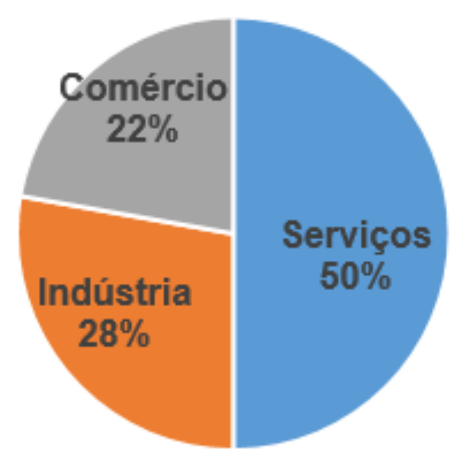

Fonte: Da autora (2018).

Com relação ao tempo que a empresa está no mercado observa-se empresas com mais de quinze anos de atuação e empresas com menos de cinco anos de atuação com o mesmo percentual de 39\% cada opção. Ainda temos $17 \%$ com dez a quinze anos de atuação e $5 \%$ com cinco a dez anos de atuação no mercado.

Gráfico 4 - Tempo de atuação da empresa

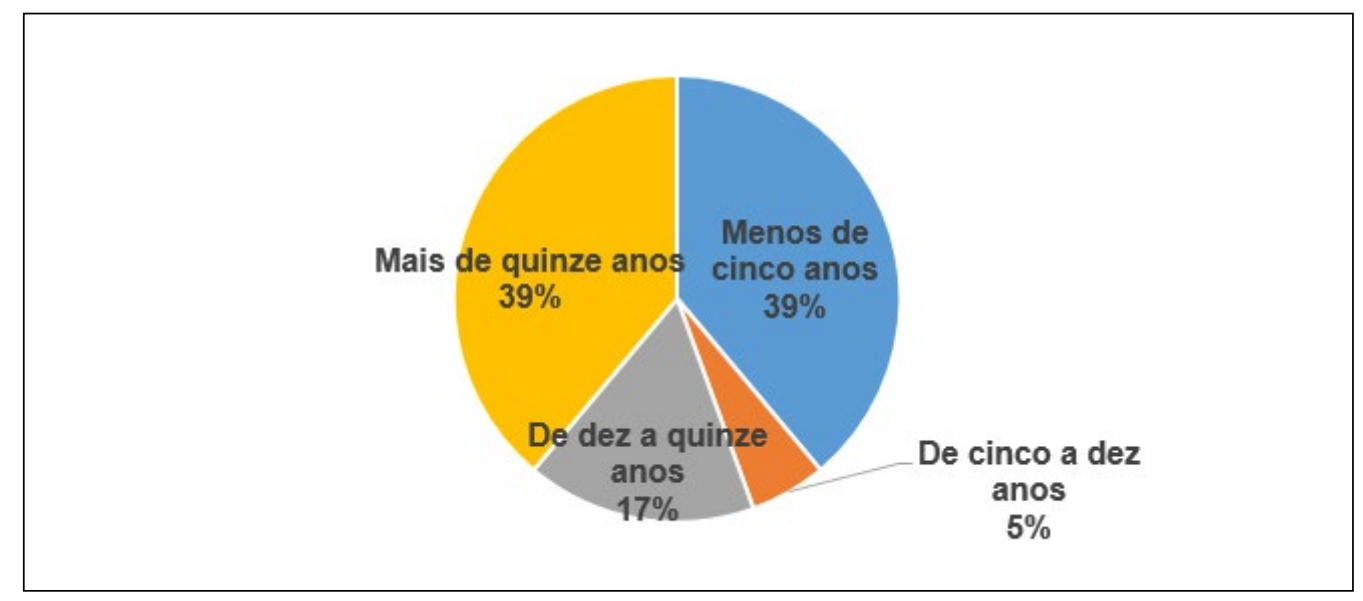

Fonte: Da autora (2018). 
Ao adentrar no contexto da comunicação, procurou-se compreender mais sobre a entendimento da empresa sobre ela mesma e seu público. Assim, questionou-se qual o público que a empresa busca atingir, onde 30\% buscam atingir adultos (independente do gênero), 17\% procuram atender o público jovem, $15 \%$ têm predisposição para atender mulheres, $13 \%$ almejam os homens, $11 \%$ buscam atender aos adolescentes, $10 \%$ as crianças e apenas $4 \%$ têm atuação junto aos idosos.

Gráfico 5 - Público-alvo que busca atingir

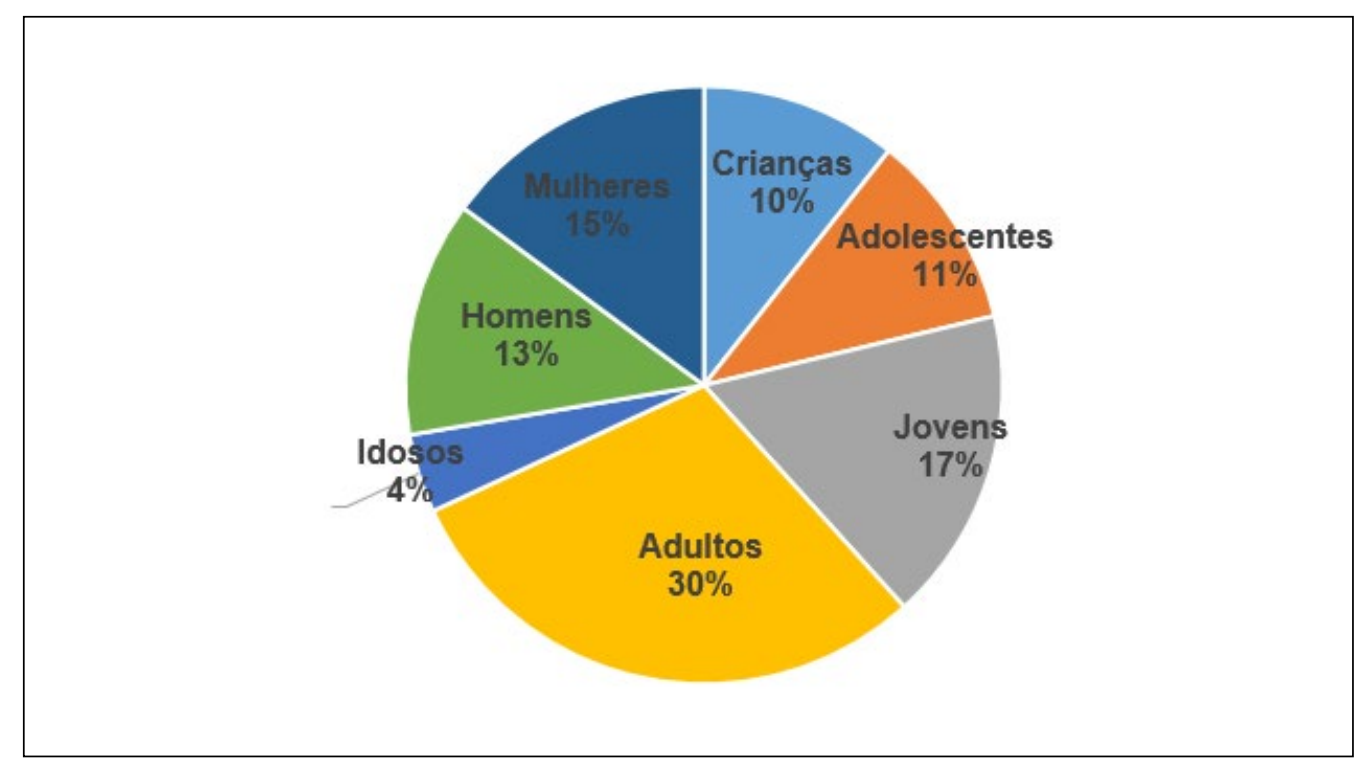

Fonte: Da autora (2018).

Destaca-se que saber qual o público que a empresa pretende atingir é fundamental, pois desta forma as empresas criam estratégias de relacionamento que almejam aplicar ações para atingi-los, mobilizando relacionamentos duradouros e eficientes com os clientes (KUNSCH, 2009).

Ao serem questionados se há pessoal designado para atuar com comunicação estratégica digital, $72 \%$ responderam que não há pessoal designado para esta função e apenas $28 \%$ revelam ter pessoal para trabalhar com as estratégias de comunicação digital. O que também influencia nas respostas sobre a frequência de atualizações dos meios digitais da instituição, onde os maiores percentuais estão concentrados em atualizações semanais $(44 \%)$ e mensais $(28 \%)$, apenas $22 \%$ fazem atualizações diárias no processo de comunicação com seu público, ainda há $6 \%$ que só atualizam mensalmente. 


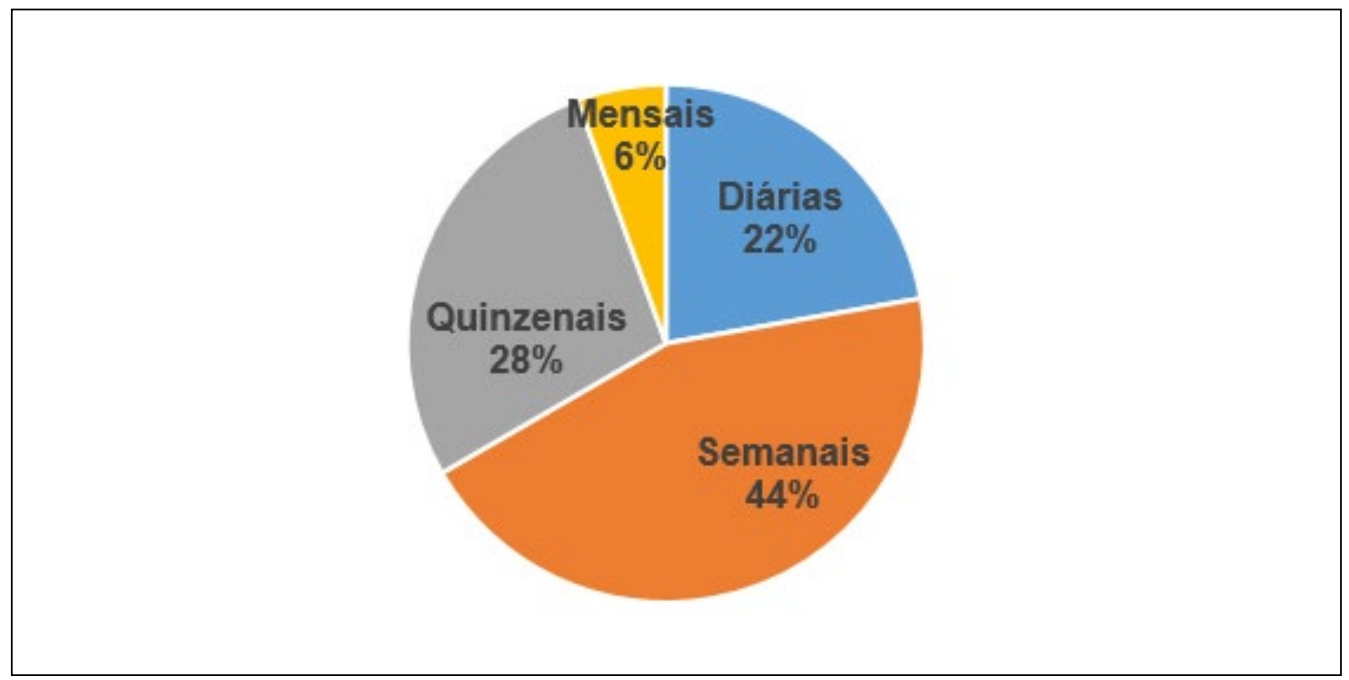

Fonte: Da autora (2018).

Para Machado (2012) é fundamental que as atualizações nas redes sociais sejam realizadas frequentemente, porém deve-se ter o bom senso de não encher a caixa de e-mail do cliente, por exemplo; já os fanáticos por jogos adorarão receber e-mails diários com links de jogos gratuitos ou lançamento. Por isso é fundamental que a empresa conheça seu cliente e entenda o quanto ele quer ser atualizado, mas, normalmente, atualizações quinzenais, mensais ou mais esporádicas podem ser percebidas negativamente pelo público.

Outro ponto relevante, foi entender com a empresa percebe sua imagem junto ao cliente, onde $94 \%$ responderam ser boa, apenas $6 \%$ responderam regular, mas é interessante que nenhuma empresa considera sua imagem ótima, muito menos ruim ou péssima. Aqui enfatiza-se que as empresas precisam se posicionar para uma imagem ótima, buscar excelência no serviço que prestam ou produto que oferecem, encantar seu público, precisam superar as expectativas de seus clientes.

Também questionou-se se o respondente conhece comunicação estratégica, $78 \%$ responderam que sim e $22 \%$ não conhecem comunicação estratégica digital. Continuando a compreensão dessa temática, pediu-se explicações sobre este entendimento aos que responderam sim, para esta análise agrupou-se as respostas em que o sentido ou as várias entonações permeavam para um mesmo entendimento de forma a desenvolver um gráfico. Assim, $44 \%$ falam que comunicação estratégica digital é planejar e criar estratégias para atingir o público-alvo por meios digitais, 19\% citam que a comunicação estratégica digital são meios digitais (redes sociais, sites, internet, etc.), 19\% falam que este novo formato de comunicação busca interagir com o público, 
ainda obteve-se $6 \%$ para cada uma das nuances a seguir: conhecer o público, promover a empresa e agilidade para atingir o cliente.

Gráfico 7 - Entendimento sobre comunicação estratégica digital

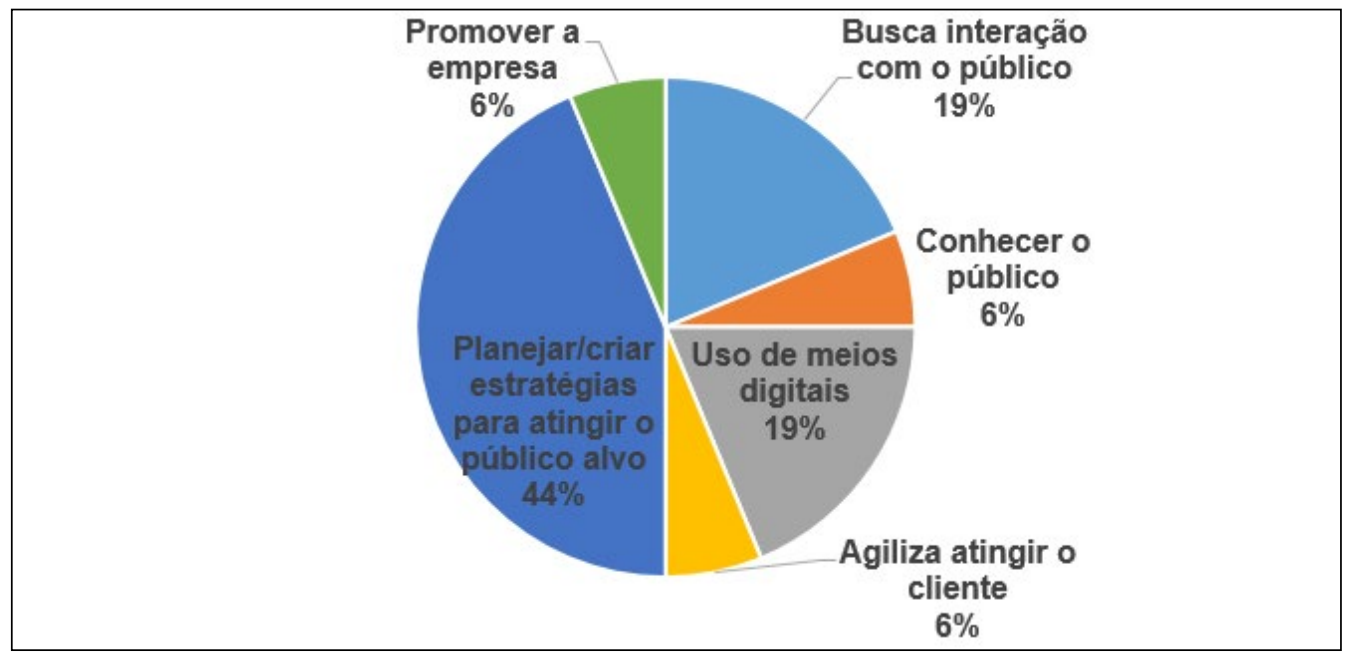

Fonte: Da autora (2018).

Os respondentes convergem com o entendimento de autores como Machado (2012), Nasser (2006) e Cerqueira e Silva (2011) que de forma a completarem-se enfatizam as ações planejadas nos novos espaços midiáticos estabelecendo relacionamento com o público-alvo. Da mesma forma que os autores, os respondentes em um conjunto de respostas completam-se e chegam a um entendimento sobre a comunicação estratégica digital.

Percebeu-se que mesmo que alguns respondessem na questão anterior não saber o que era essa nova forma de comunicação, conseguiram responder questões específicas sobre o tema, mesmo que em todas as perguntas teve-se o cuidado de dar como opção de resposta: "não sei" e/ou "não trabalhamos com comunicação estratégica".

Adiante, outro questionamento envolveu entender os benefícios que a empresa busca com a comunicação estratégica digital, onde $48 \%$ pretendem divulgar a marca, $42 \%$ responderam que buscam ampliar as vendas, 5\% almejam ampliar o número de clientes e $5 \%$ responderam que buscam interagir com o público. Com relação ao investimento que a empresa faz em comunicação estratégica digital, percebeu-se que estes são baixos, $45 \%$ fazem investimentos de até $\mathrm{R} \$ 500,00$ mensais, $22 \%$ não investem; nos valores de investimentos de $\mathrm{R} \$ 500,01$ a $\mathrm{R} \$ 1.000,00$, de $\mathrm{R} \$ 1.000,01$ a $\mathrm{R} \$ 2.000,00$ e de $\mathrm{R} \$ 2.000,01$ a $\mathrm{R} \$ 3.000,00$ mensais obteve-se $11 \%$ para cada opção, salienta-se que nenhuma empresa investe mais de $\mathrm{R} \$ 3.000,00$ em comunicação estratégica digital. 
Gráfico 8 - Investimento em comunicação estratégica digital

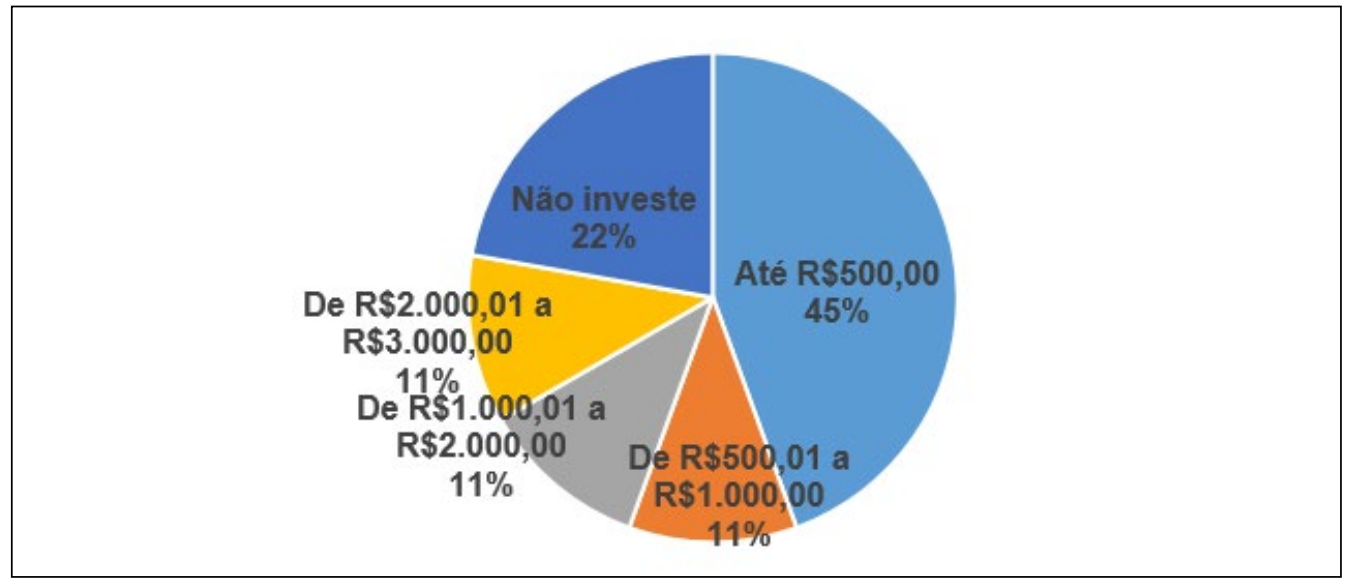

Fonte: Da autora (2018).

Com relação as formas que a empresa busca comunicar-se digitalmente com seu público, 18\% utilizam o Facebook, 16\% o Whatsapp, 16\% e-mail, 15\% têm sites, $9 \%$ atuam com o Instagram, $6 \%$ trabalham com o Twitter, ainda há outros meios com menor incidência como portais de notícias, chat on-line, SMS e MMS, Blog e Linkedin, também há empresas que estão em processo de organização da comunicação estratégica digital e outros meios que não são utilizados como: flickrs e fóruns de discussão.

Gráfico 9 - Formas de comunicação estratégica digital

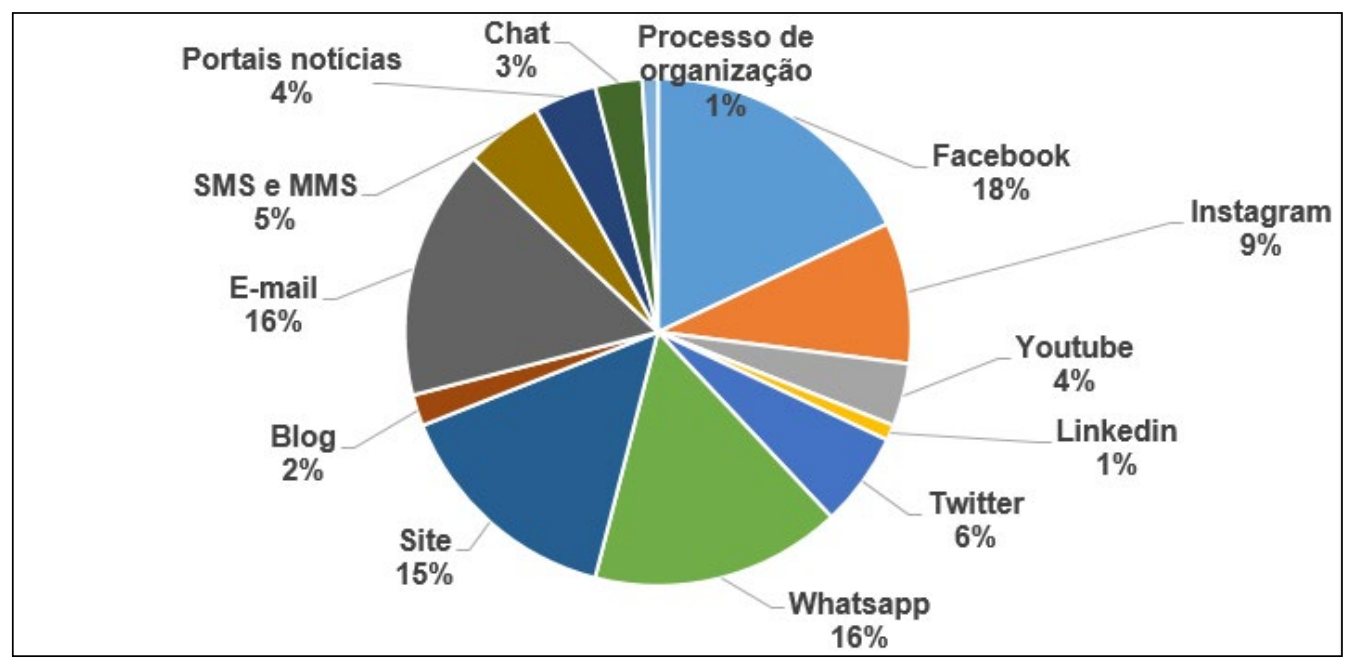

Fonte: Da autora (2018). 
Henrique (2008) traz canais de comunicação que são utilizados no âmbito digital: intranet, rede social corporativa, blog, newsletter digital, e-mail, videoconferência, etc. $\mathrm{O}$ autor também destaca que a comunicação digital proporciona maior facilidade para interagir com o público-alvo. Segundo Schuler (2004) as empresas precisam analisar métricas constantemente para entender se as estratégias de comunicação estão atingindo os resultados que esperam.

Outra questão envolveu entender se a empresa analisa a comunicação estratégica digital, em que $72 \%$ responderam que sim, $17 \%$ não e $11 \%$ não sabem ou não atuam nessa área. Aprofundando o contexto analítico, as ferramentas que as organizações mais utilizam para analisar a comunicação estratégica digital é Google Analistics (54\%), Ferramenta própria desenvolvida pela empresa $(13 \%)$, Socialmetrix $(8 \%)$ e Webtrands $(4 \%)$, ao que $21 \%$ não sabem se a instituição utiliza alguma ferramenta ou disseram que não atuam com comunicação estratégica digital. Outras métricas não obteve-se respostas.

Gráfico 10 - Ferramentas de análise da comunicação estratégica digital

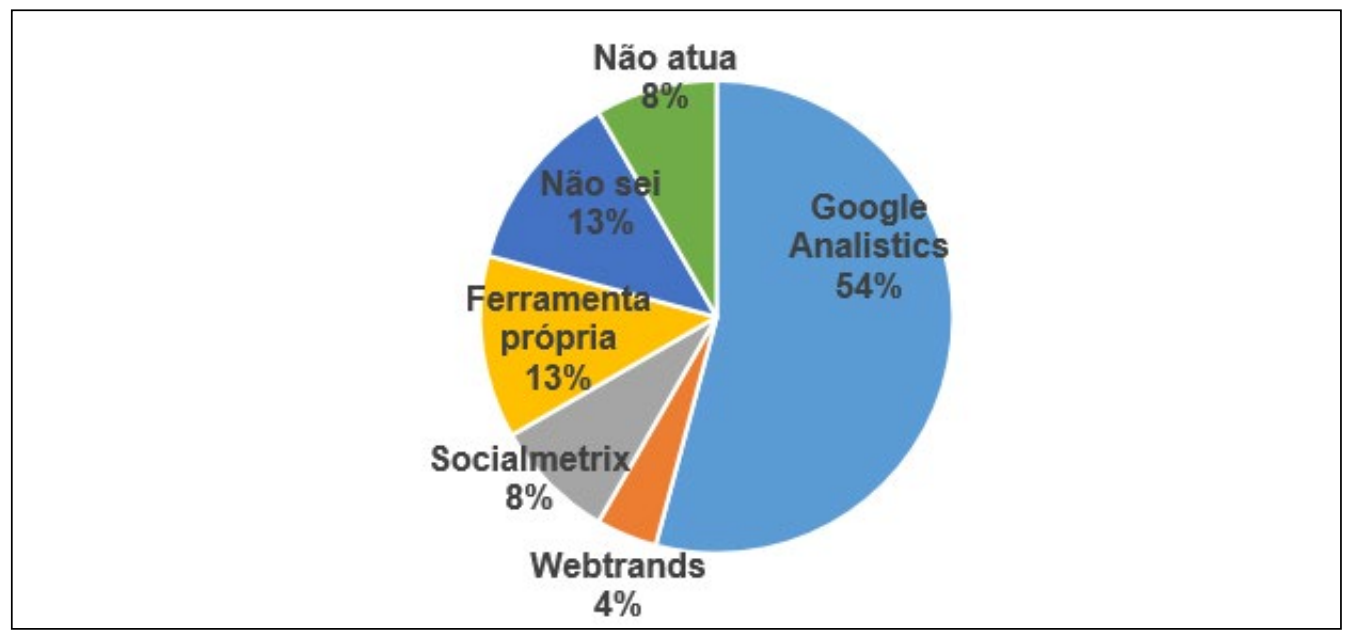

Fonte: Da autora (2018).

Ao serem questionados se a empresa adota alguma estratégia de comunicação digital, 67\% responderam que a empresa não adota nenhum planejamento neste sentido e 33\% responderam que sim, a empresa adota estratégias de comunicação digital. Ao tabular as respostas, de forma a entender estatisticamente as estratégias, percebeu-se que $43 \%$ realizam um planejamento estratégico de comunicação digital por meio de equipes (em reuniões, etc), $29 \%$ realizam ações e transmitem informações planejadas ao público-alvo, $29 \%$ atuam com patrocínios, impulsionamentos nas redes, anúncios nos meios digitais para atingir os clientes. É ponderável considerar que o planejamento é ponto comum em todas as respostas, mesmo que ocorram publicações pagas, 
estas também tem planejamento, ou seja, o planejamento é fundamental na comunicação estratégica digital.

Por fim, buscou-se perceber se ocorreram vantagens e desvantagens na comunicação estratégica digital. No âmbito das vantagens, $20 \%$ enfatizam que ocorreu melhora na imagem da empresa com a comunicação estratégica digital, $17 \%$ perceberam aumento de vendas, $17 \%$ responderam haver aumento de clientes, $11 \%$ relaram aumento na velocidade de transmissão das informações, $11 \%$ perceberam maior alcance das informações e ações da empresa divulgadas nos meios digitais, $10 \%$ conheceram melhor seu público, $7 \%$ diminuíram custos de comunicação, $5 \%$ melhoram a comunicação com o público e $2 \%$ não efetivaram a implantação da comunicação estratégica digital.

Gráfico 11 - Vantagens da comunicação estratégica digital

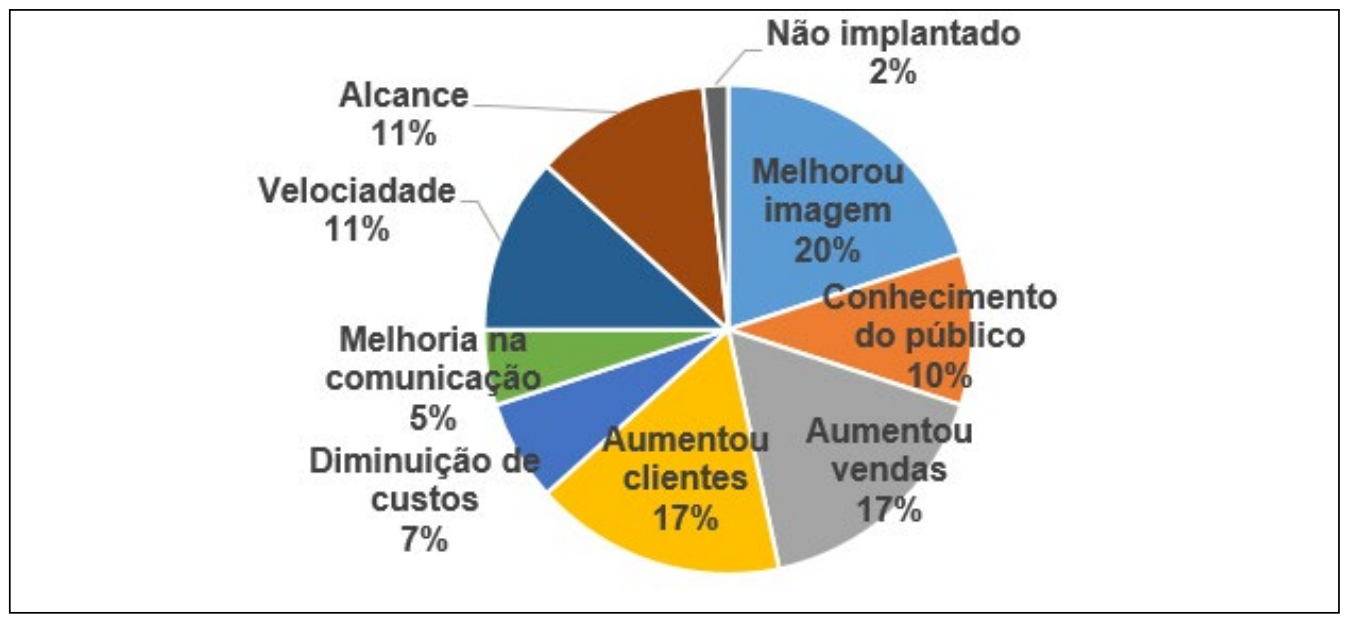

Fonte: Da autora (2018).

Com relação às desvantagens, 33\% não perceberam desvantagens na comunicação por meios digitais, $22 \%$ tiveram problemas com falsas mídias, $22 \%$ disseram ter como desvantagem a diminuição do contato direto com o cliente, $11 \%$ relataram problemas com comentários e rejeições à marca, $6 \%$ revelam ter aumentado os custos de comunicação e $6 \%$ não tem opinião formada sobre o tema. 
Gráfico 12 - Desvantagens da comunicação estratégica digital

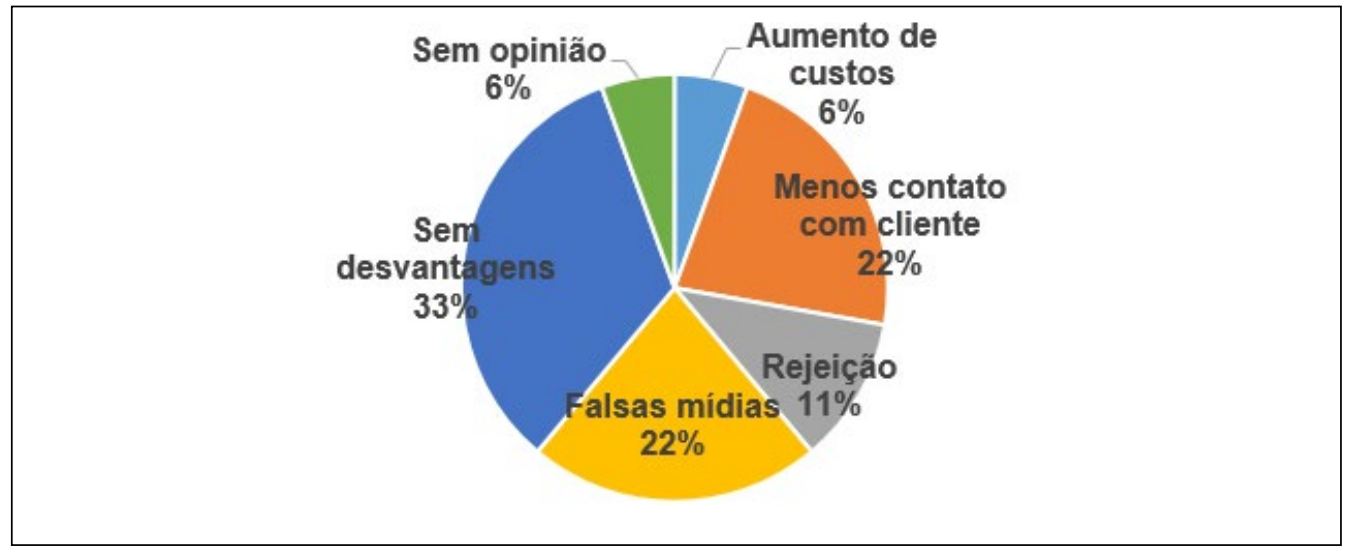

Fonte: Da autora (2018).

\section{CONSIDERAÇÕES FINAIS}

Pondera-se que em se tratando de empresas situadas no Vale do Taquari/RS há variação de faturamento, sendo empresas de pequeno a grande porte, inclusive os ramos de atuação envolvem todos os setores: indústria, comércio e serviços, ainda encontramos empresas recém instituídas até as que estão há anos no mercado.

Ao adentrarmos no contexto do público-alvo, sabe-se que todas têm interesses definidos, sabem quem precisam atingir, sendo que a maioria atua com público adulto e jovem; outrossim, a maior parte das empresas não têm pessoal designado para atuar com estratégia digital o que influencia na frequência de atualizações junto aos meios digitais que a instituição utiliza, ocorrendo, normalmente, de forma semanal ou mensal. Outro ponto a destacar refere-se ao investimento em comunicação estratégica digital, significadamente baixo (até $\mathrm{R} \$ 500,00$ mensais), mas justifica-se pelo fato das empresas utilizarem meios gratuitos de comunicação, principalmente: Facebook, Whatsapp e Instagram; entretanto elas têm custos com manutenção de site e e-mail corporativo. Ainda, apontam como a principal ferramenta de análise dos meios digitais o Google Analistics, que é um software ofertado gratuitamente ou, opcionalmente, pode ser pago.

Mais da metade dos respondentes têm conhecimento do que vem a ser comunicação estratégica digital, observando-se que envolve planejamento e estratégias para comunicar-se com o público utilizando-se de meios digitais, como redes sociais, sites, internet, entre outros. As empresas buscam atingir o público da empresa, promover a marca e torna o processo de comunicação mais rápido. 
Ainda, mesmo que a maioria das empresas não adotam estratégias de comunicação digital, as que adotam realizam o trabalho por meio de uma equipe, planejam suas ações e informações a serem transmitidas e atuam com patrocínios, impulsionamentos e anúncios junto ao público-alvo, o que denota formas que a instituição desenvolve a comunicação estratégica nessa era da tecnologia e da informação.

Com relação as vantagens e desvantagens percebidas no processo de comunicação digital, enfatizam as vantagens de melhoria da imagem da empresa, aumento das vendas e dos clientes, maior velocidade na transmissão das informações, ao mesmo tempo que, o alcance das informações e ações também é maior. Além disso, a maioria dos respondentes não percebem desvantagens na comunicação digital e os poucos que trazem estas problemáticas informam problemas com falsas mídias, diminuição do contato com o cliente, problemas com comentários e rejeições à marca ou aumento nos custos de comunicação.

Por fim, afirma-se que todos os objetivos propostos neste estudo foram atingidos, pois conseguiu-se identificar os meios de comunicação estratégica digital utilizados pelas empresas do Vale do Taquari.

\section{REFERÊNCIAS}

ARAUJO, C. A web 2.0 no cenário da comunicação organizacional. In: Simpósio Nacional ABCiber, 5, 16 a 18 nov. 2011. Anais... Florianópolis: UDESC/UFSC, 2011. p. 1-15.

BARBEIRO, H. Crise e comunicação corporativa. São Paulo: Globo, 2010.

CERQUEIRA, R.; SILVA, T. Mensuração em mídias sociais: quatro âmbitos de métricas. In: CHAMUSCA, M.; CARVALHAL, M. (Orgs.). Comunicação e marketing digitais: Conceitos, práticas, métricas e inovações. Salvador: VNI, 2011. p. 119-141.

CHEMIN, B.F. Manual da Univates para trabalhos acadêmicos: planejamento, elaboração e apresentação. 3. ed. Lajeado: Ed. da Univates, 2015.

CHURCHILL, Gilberto A.; PETER, J. Paul. Marketing criando valor para o cliente. 2. ed. São Paulo: Saraiva, 2000.

HENRIQUE, T. Os tipos de comunicação organizacional. LinkedIn, 24 jan. 2018. Disponível em: <https:/ / pt.linkedin.com/pulse/os-tipos-decomunica $\% \mathrm{C} 3 \% \mathrm{~A} 7 \% \mathrm{C} 3 \% \mathrm{~A} 3 \mathrm{o}-$ organizacional-thales-henrique $>$. Acesso em: 30 jan. 2018.

KOTLER, Philip; ARMSTRONG, Gary. Princípios de marketing. 7. ed. Rio de Janeiro: Copyright, 1998.

KUNSCH, M.M.K. (Org). Gestão estratégica em comunicação organizacional e relações públicas. 2. ed. São Caetano do Sul: Difusão, 2009. 
LIMA, M.D.C.; ABBUD, M.E.O. Comunicação organizacional: Histórico, conceitos e dimensões. In: Congresso de Ciências da Comunicação na Região Norte, 14, 28 a 30 mai. 2015. Anais... Manaus: Intercon, 2015. p. 1-15.

LOCK, M.; BALDISSERA, R. Comunicação política on-line: estratégias de administração da visibilidade no ambiente da Web 2.0. 2010. 15f. Artigo (PósGraduação em Comunicação e informação) - Universidade Federal do Rio Grande do Sul, Porto Alegre, 2010.

MACHADO, J. Estratégias de comunicação da Petrobrás no contexto da convergência midiática. 2012. 185f. Dissertação (Mestrado em Comunicação) Universidade Federal de Santa Maria, Santa Maria, 2012.

MARCONI, M.A.; LAKATOS, E.M. Fundamentos de metodologia científica. 5. ed. São Paulo: Atlas 2003.

NASSER, P. Comunicação empresarial: Estratégia de organizações vencedoras. São Paulo: ABERJE, 2006. v. 2.

RIBEIRO, Maria E. Estratégias de comunicação organizacional digital: o estudo de caso da Embrapa. 2014. 260f. Dissertação (Mestrado em Comunicação Social) Universidade Metodista de São Paulo, São Paulo, 2014.

SCHULER, M. Comunicação estratégica. São Paulo: Atlas, 2014.

SEBRAE. Ramos de atividades. 2018. Disponível em: <http:/ / www.sebrae.com.br / sites/PortalSebrae/artigos/ramos-de-atividades,8ef89e665b182410VgnVCM100000b2 72010aRCRD>. Acesso em: 21 fev. 2018.

TELLES, A. Apontamentos sobre métricas em comunicação e marketing digital. In: CHAMUSCA, M.; CARVALHAL, M. (Orgs.). Comunicação e marketing digitais: Conceitos, práticas, métricas e inovações. Salvador: VNI, 2011. p. 84-93. 


\section{APÊNDICE A - Questionário sobre comunicação estratégica digital}

\section{Comunicação Estratégica Digital}

Prezado, sou Rosane Sott Bona, estou cursando pós graduação em MBA em Marketing na Univates e estou realizando uma pesquisa para o artigo de final de curso intitulado "Empresas do Vale do Taquari e Comunicação Estratégica Digital", que tem por objetivo identificar como as empresas do Vale do Taquari utilizam a comunicaçăo estratégica digital para se relacionar com os seus clientes. Portanto, peço sua colaboração em responder este breve questionário. Saliento que todos os dados garantem o sigilo do respondente. Fico à disposiçăo para esclarecimento pelo fone (51) 996360582 . Att, Rosane S. Bona.

*Obrigatório

\section{Perfil}

1. Qual seu setor de atuação dentro da empresa? * Marcar apenas uma oval.

Diretoria
Gerência
Comercial
Financeiro
Contábil
$\square$ Recursos Humanos
$\square$ Relações Públicas

2. Qual o faturamento médio mensal da sua empresa? * Marcar apenas uma oval.

Até R\$100.000,00 mensais

De $\mathrm{R} \$ 100.000,01$ a $\mathrm{R} \$ 500.000,00$ mensais

De R\$500.000,01 a R\$1.000.000,00 mensais

De R\$1.000.000,01 a 5.000.000,00 mensais

De $5.000 .000,01$ a $10.000 .000,00$ mensias

Acima de R\$10.000.000,01 mensais

3. Qual o ramo de atuação de sua empresa? * Marcar apenas uma oval.

Indústria

Comércio

Serviços

4. Há quantos anos a empresa foi fundada? * Marcar apenas uma oval.

Menos de cinco anos

De cinco a dez anos

De dez a quinze anos

Mais de quinze anos 


\section{Comunicação}

5. Que tipo de público sua empresa busca atingir? *

Marque todas que se aplicam.

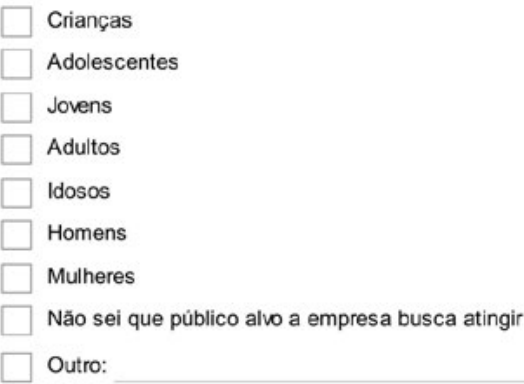

6. Sua empresa tem pessoal designado para trabalhar com comunicação estratégica digital? *

Marcar apenas uma oval.

Sim

Não

Não sei

7. Com que frequência sua empresa atualiza seus meios de comunicação digital (redes sociais, blogs, envio de e-mail's, etc)? *

Marcar apenas uma oval.

Não atuamos com comunicação digital

Atualizações diárias

Atualizações semanais

Atualizaçōes quinzenais

Atualizaçōes mensais

Atualizações bimestrais

8. Qual a imagem que a empresa tem diante do seu público? * Marcar apenas uma oval.
Péssima
Ruim
Regular
Boa
Excelente

\section{Comunicação Estratégica Digital}

9. Você conhece comunicação estratégica digital? Se sim, explique o que entende por comunicação estratégica digital? * 
10. Qual o principal benefício que sua empresa busca com a comunicaçăo estratégica digital? *

Marcar apenas uma oval.

Não sei se utilizamos ou não utilizamos comunicação digital

Divulgação da marca

Audiência

Aumento de tráfego

Ampliação de vendas

Ampliação do número de clientes

Outro:

11. Quanto sua empresa investe em comunicação estratégica digital mensalmente (patrocínio em redes sociais, desenvolvimento de site, etc)?

Marcar apenas uma oval.

Não investe ou não sei se investe em comunicação digital

Até R\$500,00 mensais

De $\mathrm{R} \$ 500,01$ a $\mathrm{R} \$ 1.000,00$ mensais

De $R \$ 1.000,01$ a $R \$ 2.000,00$ mensais

De $R \$ 2.000,01$ a $R \$ 3.000,00$ mensais

Acima de $\mathrm{R} \$ 3.000,01$ mensais

12. Quais as formas de comunicação digital que sua empresa utiliza? * Marque todas que se aplicam.

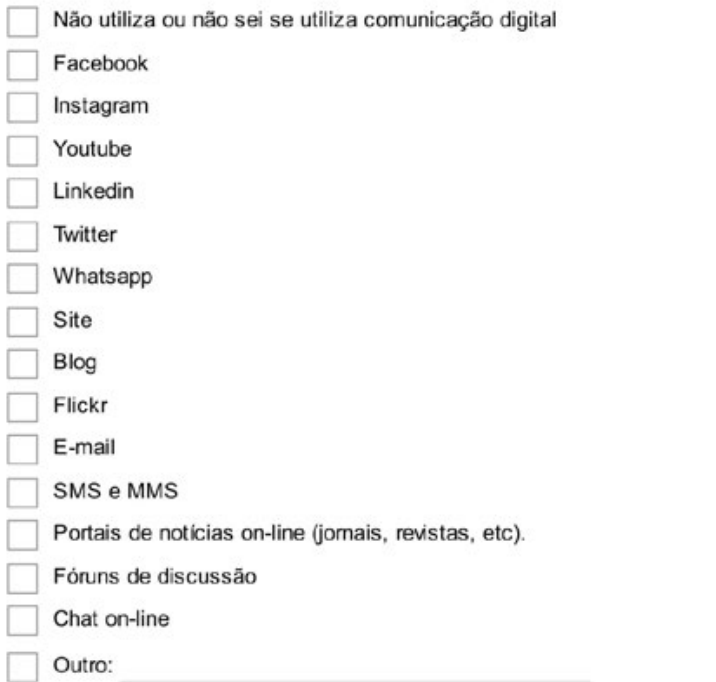

13. Sua empresa analisa resultados de comunicaçăo digital? * Marcar apenas uma oval.

Não atuamos com comunicação digital

Sim

Nāo

Năo se 
14. Qual ferramenta de análise estatística em comunicação digital sua empresa adota? * Marque todas que se aplicam.

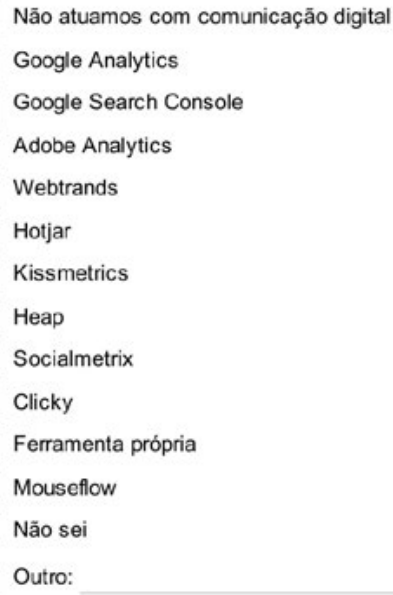

15. Sua empresa adota estratégias de comunicação digital? Se sim, como é o processo estratégico de comunicação digital? *

16. Quais as vantagens que a empresa obteve com a comunicação estratégica digital? * Marque todas que se aplicam.

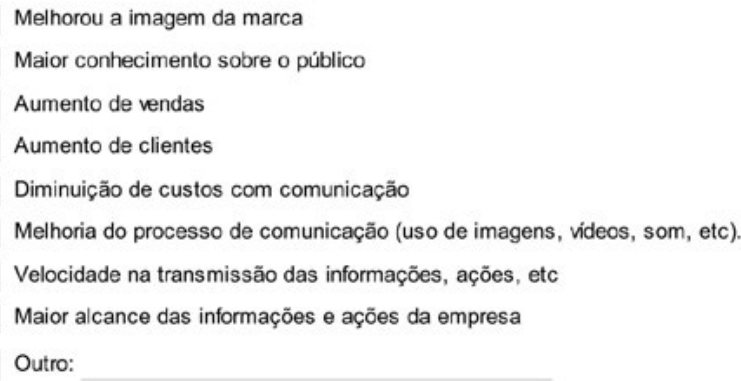

17. Quais as desvantagens que a empresa obteve com a comunicação estratégica digital? * Marque todas que se aplicam.

Aumento dos custos com patrocínios digitais

Piorou na imagem da marca

Menos contato com cliente

Problemas com comentánios e rejeições à marca ou ação

Falsas mídias com a imagem da empresa

Outro: 